\title{
Multiple endocrine neoplasia type 2A with cutaneous lichen amyloidosis
}

\author{
Rakhi Malhotra, ${ }^{1}$ Hiya Boro (1) ,' Shamim Ahmed Shamim, ${ }^{2}$ Rajesh Khadgawat ${ }^{1}$
}

${ }^{1}$ Endocrinology and Metabolism, Army Hospital Research \& Referral, New Delhi, Delhi, India ${ }^{2}$ Nuclear Medicine, All India Institute of Medical Sciences, New Delhi, Delhi, India

\section{Correspondence to} Dr Rakhi Malhotra; rakhi.malhotra@gmail.com

Accepted 5 August 2020

\section{DESCRIPTION}

A 33-year-old woman presented with a decadelong history of a painless, gradually increasing neck swelling not associated with any compressive symptoms. She also complained of intermittent unprovoked episodes of headache, palpitations, anxiety and sweating for the past 6 months. She had similar episodes 3 years back, and perusal of old documents revealed that she had undergone right adrenalectomy for pheochromocytoma. At that time, she was also documented to have elevated serum calcitonin $(1271(<6 \mathrm{pg} / \mathrm{mL}))$, and multiple endocrine neoplasia type 2 (MEN 2) was suspected. However, further evaluation could not be done as the patient was lost to follow-up due to financial constraints. There was history of goitre in her maternal grandmother, mother and maternal uncle. Her mother and maternal uncle had also been operated for adrenal tumour and were advised neck surgery, which they had refused. On examination, she was normotensive. A firm and diffuse goitre was palpable in the neck associated with level II cervical lymphadenopathy on the left side. A hyperpigmented, pruritic, velvety plaque with fine scales was noted in the right scapular region (figure 1).

MEN 2A with cutaneous lichen amyloidosis (CLA) was suspected. Fine needle aspiration cytology from the thyroid revealed medullary thyroid carcinoma (MTC), Bethesda category VI. Serum calcitonin $(6715(<6 \mathrm{pg} / \mathrm{mL})), 24$ hours of urine metanephrines $(963.53(74-297 \mu \mathrm{g} /$ day $))$ and normetanephrines (1063 (73-808 $\mu \mathrm{g} /$ day)) were elevated. She was normocalcemic with a normal intact parathyroid hormone level. Contrast-enhanced CT scan of neck, chest and abdomen revealed multiple

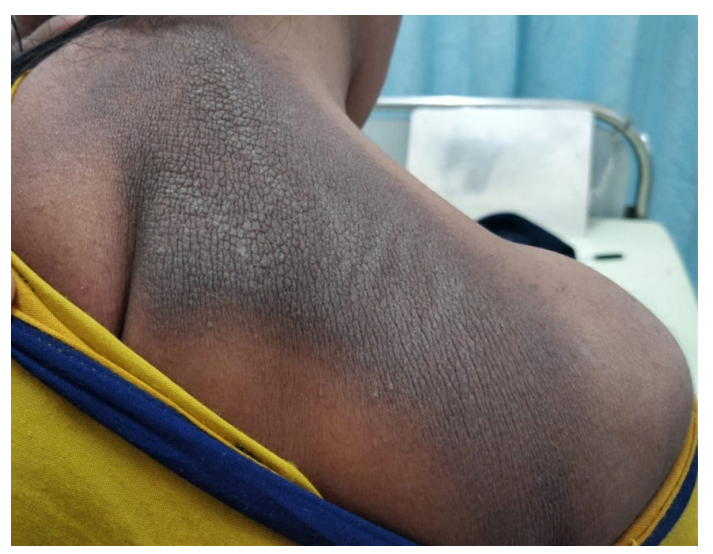

Figure 1 Cutaneous lichen amyloidosis in multiple endocrine neoplasia type 2A. Hyperpigmented, velvety plaque with fine scales in the right scapular region.

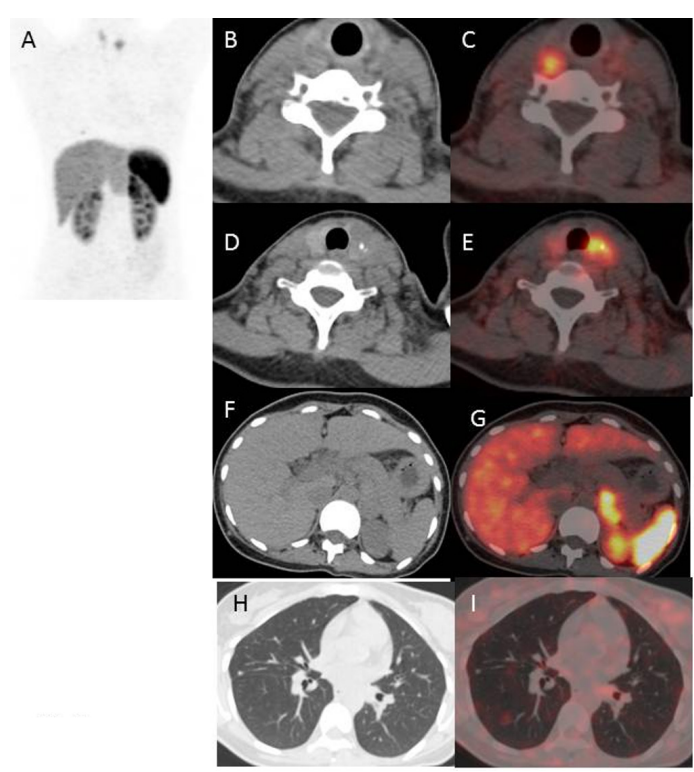

Figure 2 (A) Maximum intensity projection image of $68 \mathrm{Ga}$ DOTANOC PET-CT showing focal areas of radiotracer uptake in the neck region and left suprarenal region, corresponding hypodense lesions in both the lobes of the thyroid $(B, D)$ with the left one showing coarse calcifications. SSTR expression was noted in both the lesions in fused PET-CT images (C,E). Axial CT abdomen (F) showing enlarged left adrenal gland with SSTR expression in fused PET-CT image (G). Axial CT thorax $(\mathrm{H})$, showing a nodule in the right lung upper lobe apical segment with SSTR expression in fused PETCT image (I). PET, positron emission tomography; SSTR, somatostatin receptor.

thyroid nodules, with the largest nodule being $1.5 \times 1.2 \mathrm{~cm}$ in size with calcification, nodule in the right upper lobe of the lung and $5 \times 3.5 \times 1.7 \mathrm{~cm} \mathrm{left}$

\section{Patient's perspective}

It has been explained by my doctors that I have a malignant cancer syndrome which runs in families and involves thyroid, adrenal and parathyroid glands. It is crucial to detect thyroid malignancy early to avoid involvement of other glands and spread of the disease to other organs. There is a family history of goitre in relatives on my maternal side, but I ignored my symptoms and now have advanced disease. I am now convinced that timely screening of at-risk family members and prophylactic thyroidectomy of family members who have the genetic mutation can be curative. 
adrenal lesion with heterogeneous contrast enhancement. These lesions showed increased somatostatin receptor expression on ${ }^{68}$ Gallium-DOTANOC PET-CT scan (figure 2) consistent with MTC with lung metastasis and left adrenal pheochromocytoma. Genetic testing confirmed RET (REarranged during Transfection) codon 634 mutation confirming the diagnosis of MEN 2A.

She underwent laproscopic left adrenalectomy followed by total thyroidectomy with modified radical neck dissection and pulmonary metastasectomy and started on hydrocortisone, fludrocortisone and levothyroxine replacement. She is on outpatient follow-up. Her younger brother and daughter have tested negative for targeted RET codon 634 mutation.

MEN 2A with cutaneous lichen amyloidosis (CLA) is a rare MEN 2A variant almost exclusively associated with RET codon 634 mutation. About 35\% of patients with this mutation have CLA in their lifetime, which manifests as an intensely pruritic,

\section{Learning points}

- There has been a paradigm shift in the diagnosis of multiple endocrine neoplasia type 2 (MEN 2) syndrome with the discovery of $R E T$ gene. The disease course can be predicted based on the RET point mutation. Targeted screening approach should be used for at-risk family members, and those positive for mutation should be convinced for thyroidectomy.

- Non-endocrine manifestations like CLA should be carefully looked for in a MEN 2A kindred as it may predate the onset of MTC by years. scaly and pigmented rash, typically located in the interscapular region. ${ }^{12}$ It is a precocious marker for the presence of a mutated RET allele and the impending development of MTC in a MEN 2A kindred. ${ }^{3}$

Twitter Hiya Boro @hiya21288

Contributors RM was involved in patient care, contributed to conception and design, acquisition of data, drafted the article, gave the final approval of the version to be published and agreed to act as guarantor of the work. HB was involved in patient care, contributed to the acquisition of data, critically revised the draft for important intellectual content and gave the final approval of the version to be published. SAS contributed to the acquisition of data, critically revised the draft for important intellectual content and gave the final approval for the version to be published. RK contributed to the conception and design, critically revised the draft for important intellectual content and gave the final approval for the version to be published.

Funding The authors have not declared a specific grant for this research from any funding agency in the public, commercial or not-for-profit sectors.

Competing interests None declared.

Patient consent for publication Obtained.

Provenance and peer review Not commissioned; externally peer reviewed.

\section{ORCID iD}

Hiya Boro http://orcid.org/0000-0001-7868-8026

\section{REFERENCES}

1 Wells SA, Asa SL, Dralle H, et al. Revised American thyroid association guidelines for the management of medullary thyroid carcinoma. Thyroid 2015;25:567-610.

2 Verga U, Fugazzola L, Cambiaghi S, et al. Frequent association between men 2A and cutaneous lichen amyloidosis. Clin Endocrinol 2003;59:156-61.

3 Scapineli JO, Ceolin L, Puñales MK, et al. Men 2A-related cutaneous lichen amyloidosis: report of three kindred and systematic literature review of clinical, biochemical and molecular characteristics. Fam Cancer 2016;15:625-33.

Copyright 2020 BMJ Publishing Group. All rights reserved. For permission to reuse any of this content visit

https://www.bmj.com/company/products-services/rights-and-licensing/permissions/

BMJ Case Report Fellows may re-use this article for personal use and teaching without any further permission.

Become a Fellow of BMJ Case Reports today and you can:

- Submit as many cases as you like

- Enjoy fast sympathetic peer review and rapid publication of accepted articles

- Access all the published articles

- Re-use any of the published material for personal use and teaching without further permission

Customer Service

If you have any further queries about your subscription, please contact our customer services team on +44 (0) 2071111105 or via email at support@bmj.com.

Visit casereports.bmj.com for more articles like this and to become a Fellow 